\title{
HEALTH BEHAVIORS OF UNDERGRADUATE STUDENTS: A COMPARISON OF PHYSICAL EDUCATION AND TECHNICAL FACULTIES
}

\author{
Aleksandra Rogowska ${ }^{1}$, Bożena Wojciechowska-Maszkowska ${ }^{2}$, Dorota Borzucka ${ }^{3}$
}

\begin{abstract}
INTRODUCTION: A healthy lifestyle is related to healthy practices, such as healthy diet, avoidance of psychoactive stimulants, appropriate level of physical activity, preventive behaviors, coping with stress, positive social relationships, and adjustments. University students do not usually engage in a healthy lifestyle. Moreover, excessive alcohol drinking among students is truly a health problem.
\end{abstract}

OBJECTIVES: The primary objective of this study was to examine the association between alcohol drinking and healthy behaviors in undergraduate students from a large public technical university in the south of Poland (Europe).

METHODS: A cross-sectional study was used with participants of 283 second year undergraduate students, aged 22 years $(\mathrm{SD}=2.92)$, including $88(31 \%)$ students of Physical Education and $195(69 \%)$ students of the Technical Faculty. The study used self-administered questionnaires of the Alcohol Drinking Scale (ADS) and the Health Behavior Inventory (HBI), which includes the following subscales: healthy habits nutrition (HHN), preventive behavior (PB), positive adjustments (PA), and healthy practices (HP).

RESULTS: Alcohol drinking was negatively correlated with the total HBI and also with two subscales: HHN and PPB. The female students drank significantly less alcohol than the male students and presented with a higher level of health behavior, both in the total HBI and in the individual HBI subscales, except for PA. Students of Physical Education drank more alcohol, and scored higher in preventive behaviors, than the students of Technical Faculties.

CONCLUSION: It seems necessary to conduct general health education as part of prevention programs at the university, especially for male undergraduate students in the Physical Education faculty.

UDC Classification: 614, 796.01/.09 DOI: http://dx.doi.org/10.12955/cbup.v4.822

Keywords: alcohol drinking, healthy lifestyle, healthy behavior, undergraduates.

\section{Introduction}

A healthy lifestyle is related to healthy practices, such as healthy diet, avoidance of psychoactive stimulants, appropriate level of physical activity, preventive behaviors, coping with stress, positive social relationships and adjustments. In comparison, smoking, physical inactivity, unhealthy diet, and excessive alcohol and drug use, are important determinants of many diseases and mortality, according to the World Health Organization (World Health Organization, 2009), and results in higher health-care costs. In particular, diet and lifestyle often play a significant role in the pathogenesis of major chronic diseases, such as coronary heart disease, cancer, diabetes, and stroke. Lack of physical activity may lead to obesity and physical disability, both related to many health and psychosocial problems. According to WHO recommendations, at least half an hour of moderate-intensity physical activity on most days of the week can improve and maintain health. Unfortunately, only $31 \%$ of European adults report sufficient physical activity (Cavill, Kahlmeier, \& Racioppi, 2006).

Other risk factors, such as risky sexual behavior, forgoing social, academic, occupational, or recreational activities, high risk of physical injury, health problems such as obesity and high blood pressure, aggression, violence, motor vehicle accidents, and suicide, are usually consequences of excessive alcohol and drug use (e.g., Arria et al. 2013; Ray, Turrisi, Abar, \& Peters, 2009; Wicki, Kuntsche, \& Gmel, 2010). As suggested by studies on the health lifestyles of adolescents, males are at high risk of substance abuse, violence, and early sexual activity, whereas females have been shown to

\footnotetext{
${ }^{1}$ Aleksandra Rogowska, Institute of Psychology, University of Opole, Opole, Poland, arogowska@ uni.opole.pl

${ }^{2}$ Bożena Wojciechowska-Maszkowska, Faculty of Physical Education and Physiotherapy, Opole University of Technology, Opole, Poland, b.wojciechowska-maszkowska@po.opole.pl

${ }^{3}$ Dorota Borzucka, Faculty of Physical Education and Physiotherapy, Opole University of Technology, Opole, Poland, d.borzucka@po.opole.pl
} 
have high levels of depression and more suicide attempts (Neumark-Sztainer, 1999; Pitel, Madarasova Geckova, van Dijk, \& Reijneveld, 2010). Indeed, male students are consistently less likely than female students to be abstainers, but are more likely to consume alcohol both more frequently and in higher quantities than females (Harrell \& Karim, 2008; Kunttu \& Pesonen, 2013; Thom, 2003; Wicki et al. 2010).

There are also gender differences in health-related behavior. Generally, female students reported healthier behavior than males in regards to physical activity, healthy nutrition, and alcohol drinking (Kunttu \& Pesonen, 2013; He, Kramer, Houser, Chomitz, \& Hacker, 2004). Knowledge about healthy lifestyles, as well as a higher consciousness of responsibility for health, do not guarantee a positive attitude towards self-health, especially in the behavioral dimension (e.g., Fabelo, Iglesias, Cabrera, \& Maldonado, 2013; Kozieł, Naszydłowska, Trawczyńska, \& Czerwiak, 2003; Michalik \& WojtasŚlubowska, 2012; Romanowska-Tołłoczko, 2011). Kozieł et al. (2003) found that the majority of medical and health sciences students represented a low level of healthy practices and healthy habits in nutrition. Also, an important sample of Physical Education students, who will teach children of Health Education in the future, demonstrated rather unhealthy lifestyles and higher risk of alcohol and drug use (Górska-Kłęk, Mełeszko, \& Berner, 2011; Romanowska-Tołłoczko, 2011; Szczerbiński, Karczewski, \& Maksymowicz-Jaroszuk, 2011). Moreover, Michalik and Wojtas-Ślubowska (2012) showed that alcohol consumption among Physical Education students in Poland increases during subsequent years of study. It is important to note that the level of physical activity in Polish children and youth is insufficient, compared to other European countries (Woynarowska, Mazur, Kołoczko, \& Małkowska, 2005). Therefore, the role of Polish physical education teachers in the broad area of health education, promotion, and prevention is especially important (Huk-Wieliczuk \& Marcinkowski, 2009).

Unfortunately, there is strong evidence of the existence of an incongruous positive association between alcohol consumption and physical activity in college students (Musselman \& Rutledge, 2010). Intercollegiate athletes reported greater alcohol consumption, engaged in more frequent heavy episodic drinking, and reported more alcohol-related problems than their non-athlete peers (Grossbard et al., 2009; Hummer, LaBrie, \& Lac, 2009; Martens, Dams-O'Connor, \& Beck, 2006; Martens, Labrie, Hummer, \& Pedersen, 2008; Weaver et al., 2013; Yusko, Buckman, White, \& Pandina, 2008). Moreover, relative to non-athletes, athletes reported, not only greater alcohol use, but also more sexual partners and lower perceived risk as a cognitive mediator of unhealthy behavior (Wetherill \& Fromme, 2007). However, Lisha and Sussman (2010), in a review of such studies, suggested that participation in sport is related to higher levels of alcohol consumption, but lower levels of both cigarette smoking and illegal drug use.

Early adulthood seems to play a key role in shaping individual patterns of healthy lifestyles. College represents a significant transition period in the lives of most young people and should be an important time for interventions to reduce chronic disease risk, as suggested by Hendricks, Herbold, and Fung (2004). However, little is known about the association between current health-related behaviors and such high-risk behavior as alcohol drinking in college-age students. Some behaviors are explicitly linked to certain health problems, whereas other diseases are a consequence of the interaction of multiple behaviors (Ezzati et al., 2003; WHO, 2003). The data from various studies suggest an ambiguous relationship between physical activity, healthy eating habits, and alcohol drinking (de Vries et al., 2008; Hendricks et al., 2004). This study examines the association between alcohol drinking and health-related behaviors in undergraduate students from a large public technical university in the south of Poland (Europe). The aim of this study concerns the following questions:

1. Is there a relationship between several dimensions of health-related behavior, such as healthy diet, preventive behavior, positive adjustments, healthy practices, and alcohol drinking?

2. Are there gender differences in the health lifestyle of students?

3. Are there differences in health-related behaviors between samples of students representing the Physical Education (PE) and Technical faculties (TF)?

If there is a relationship between these variables, prevention programs at universities should include not only strategies related to alcohol and drug, but also those related to other health-related behaviors. Special health assistance should concern PE students, who will teach Health Education in schools in 
the future. Because lifestyle is associated with its cultural and social context, it seems important to continuously monitor changes in health behaviors in relation to the process of transformation of civilization in many countries of world. The analysis of protective and risky factors in the ecosystem may improve health promotion and prevention, as suggested in the concept of resilience (Folke et al., 2002).

\section{Methods}

\section{Participants}

The participants were 283 second-year undergraduate students of a medium-sized public university in the south-west of Poland. All participants were Caucasian and White, aged 22 years ( $S D=2.92)$, with a prevalence of males $(\mathrm{n}=196 ; 69 \%)$. The sample included $88(31 \%)$ students of Physical Education (PE), and 195 (69\%) students of the Technical Faculty (TF; mechanical engineering, informatics, and management).

\section{Procedure}

Surveys were conducted at the university, during classes, with the consent of lecturers by prior arrangement. Two standardized questionnaires: The Health Behavior Inventory (HBI) and the Alcohol Drinking Scale (ADS), were administered in the study. Participation in the questionnaire was voluntary and anonymous. This study was approved by the local Bioethics Committee. The collected data was analyzed using the Statistica 10 software.

\section{Measures}

The Health Behavior Inventory (HBI) was created by Juczyński (2009). According to Gochman (1988) the definition of health behavior is "personal attributes such as beliefs, expectations, motives, values, perceptions, and other cognitive elements; personality characteristics, including affective emotional states and traits; and overt behaviour patterns, actions and habits that relate to health maintenance, to health restoration and to health improvement" (p. 3). The construction of HBI was based on previous assessments to measure health-related behaviors, such as the General Preventative Health Behaviors Checklist (Amir, 1987), and the Reported Health Behaviors Checklist (Prohaska, Leventhal, Leventhal, \& Keller, 1985).

The HBI is a self-reported questionnaire, consisting of 25 statements describing various health-related behaviors, with a 5-degree Likert scale of frequency ( 1 - almost never, 2 - rarely, 3 - from time to time, 4 - often, and 5 - nearly always). The indicator of total health-related behaviors is a sum of all answers, ranging from 24 to 120 points. A healthier lifestyle is related to a higher total HBI value. According to the test procedure, the results were divided into four categories measuring particular aspects of health-related behaviors: healthy habits nutrition (HHN; type of foods, well-balanced diet), preventive behavior ( $\mathrm{PB}$; health recommendations, health and disease information), positive adjustments (PA; psychological factors, such as avoiding too strong emotions, stress, anxiety, and depressive situations), and healthy practices (HP; sleep habits, recreation and physical activity). Juczyński (2009) reported satisfactory reliability for total HBI (Cronbach's $\alpha=0.85$ ), and for all subscales (with Cronbach's $\alpha$ ranging between 0.60 and 0.65). In the present study, the internal consistency was also satisfactory for the total HBI and sufficient for the particular scales HHN, PB, PA, and HP, with Cronbach's alphas of $0.81,0.79,0.66,0.63$, and 0.56 , respectively.

The Alcohol Drinking Scale (ADS) is a 5-item self-reported scale derived from the questionnaire 'Students 2004', that was applied in the framework of the program 'Universities Free from Addictions' (Sierosławski, 2004). The ADS consists of five questions related to the degree of frequency and quantity of alcohol drinking (such as beer, wine, and spirits) during the last 12 months and 30 days. Individuals could answer on a scale (ranging from 5 to 7 degrees). The total ADS is a sum of all questions (ranging from 10 to $54, \mathrm{M}=33.61, \mathrm{SD}=8.9$ ); a high result indicated excessive alcohol drinking, with a high risk of alcohol abuse or dependence. The reliability of the ADS was high, with a coefficient of internal consistency, Cronbach's $\alpha$ of 0.86 .

\section{Results}

Descriptive statistics for the ADS and the HBI scales are shown in Table 1 (mean, standard deviation, range, and Pearson's $r$ correlation coefficient). The ADS was negatively correlated with total HBI 
(Figure 1). However, regression analysis indicated that alcohol drinking explained only $3 \%$ of the overall variance of healthy behavior, $\mathrm{R}^{2}=0.03, \mathrm{~F}(1,281)=7.34, \mathrm{p}<0.01$. Also, two subscales of the $\mathrm{HBI}$, namely HHN and PB, were correlated with the ABS. Consistent with expectations, all subscales of the HBI were correlated with each other.

The differences between male and female students for the ADS and BHI scales are shown in Table 2. The multivariate analysis of variance (MANOVA) for the HBI Scales (HHN, PB, PA, and HP) as a dependent variable, and gender (female and male) as a categorical factor, showed a significant main effect, Rao $(4,278)=5.95, \mathrm{p}=0.001$, Wilkins' $\lambda=0.92$. There were significant gender differences in terms of healthy habits nutrition: $\mathrm{F}(1,281)=21.01, \mathrm{p}=0.00001$; preventive behaviour: $\mathrm{F}(1,281)$ $=9.93, \mathrm{p}=0.01$; and healthy practices: $\mathrm{F}(1,281)=4.46, \mathrm{p}=0.04$; but not for positive adjustments: $\mathrm{F}(1,281)=0.67, \mathrm{p}=0.42$. The differences between the means in the particular groups and scales are demonstrated in Figure 2.

The differences between the PE and TF samples of students in the ADS and HBI scales are shown in Table 2. The PE students drink significantly more alcohol than the TF students. The MANOVA for the HBI scales (HHN, PB, PA, and HP) as a dependent variable, and Faculty (PE and TF) as a categorical factor, showed a significant main effect, Rao $(4,278)=2.86, p=0.03$, Wilkins' $\lambda=0.96$. However, among four scales of HBI, only preventive behavior: $\mathrm{F}(1,281)=8.61, \mathrm{p}=0.004$; significantly differentiated students of physical education and technical faculties (see Figure 3 for more details).

Table 1: Descriptive statistics for Alcohol Drinking Scale and Health Behavior Inventory scales

\begin{tabular}{|c|c|c|c|c|c|c|c|c|c|}
\hline \multicolumn{2}{|r|}{ Scales } & $\mathrm{M}$ & SD & Range & 2. & 3. & 4. & 5. & 6. \\
\hline 1. & Alcohol Drinking Scale & 32.00 & 10.00 & $10-62$ & $-0.16^{* *}$ & $-0.13 *$ & $-0.16^{* *}$ & -0.08 & -0.10 \\
\hline 2. & Health Behaviour Inventory & 73.19 & 13.36 & $33-115$ & & $0.80 * * *$ & $0.82 * * *$ & $0.71 * * *$ & $0.73 * * *$ \\
\hline 3. & Healthy Habits Nutrition & 17.28 & 4.59 & $6-30$ & & & $0.55 * * *$ & $0.36^{* * *}$ & $0.49 * * *$ \\
\hline 4. & Preventive Behaviour & 16.74 & 4.73 & $6-29$ & & & & $0.51 * * *$ & $0.39 * * *$ \\
\hline 5. & Positive Adjustments & 20.17 & 3.85 & $8-30$ & & & & & $0.40 * * *$ \\
\hline 6. & Healthy Practices & 18.81 & 4.09 & $6-30$ & & & & & \\
\hline
\end{tabular}

Note: $\mathrm{N}=283 ; * \mathrm{p}<0.05 ; * * \mathrm{p}<0.01 ; * * * \mathrm{p}<0.001$

Source: Authors

\section{Discussion}

Generally, university students in this study showed a pattern of drinking, consistent with the 'wet' drinking culture that characterizes Polish adults, in which consumption of spirits is rather high, and binge drinking is quite common (Rehn, Room, \& Edwards, 2001). Moreover, students who were more likely to drink alcohol were less motivated towards a healthy lifestyle, especially with regard to healthy diet and preventive behavior. Excessive drinking may be related to poor consciousness of negative consequences and lack of interest in self-health. Lorente, Souville, Griffet, and Grélot (2004) showed that higher alcohol use among French high-school students was associated with male gender, participation in sports, daily smoking, and perception of poor health.

This study indicated that several scales of the HBI, such as healthy diet, preventive behavior, positive adjustments, and healthy practices, are positively correlated with each other. Association between several health-related behaviors seems to be consistent with the study by Dams-O'Connor, Martens, and Anderson (2006), which found a positive relationship between disordered eating behaviors and heavy alcohol use in a sample of female college students at a large public university in the northeast region of the United States. In addition, data from a survey study among 93 first-year female college student in the U.S. suggested that diet, physical activity, sexual activity, smoking, alcohol consumption, and drug use occurred together (Hendricks et al., 2004). 
Figure 1: Correlation between Health Behavior Inventory and Alcohol Drinking Scale

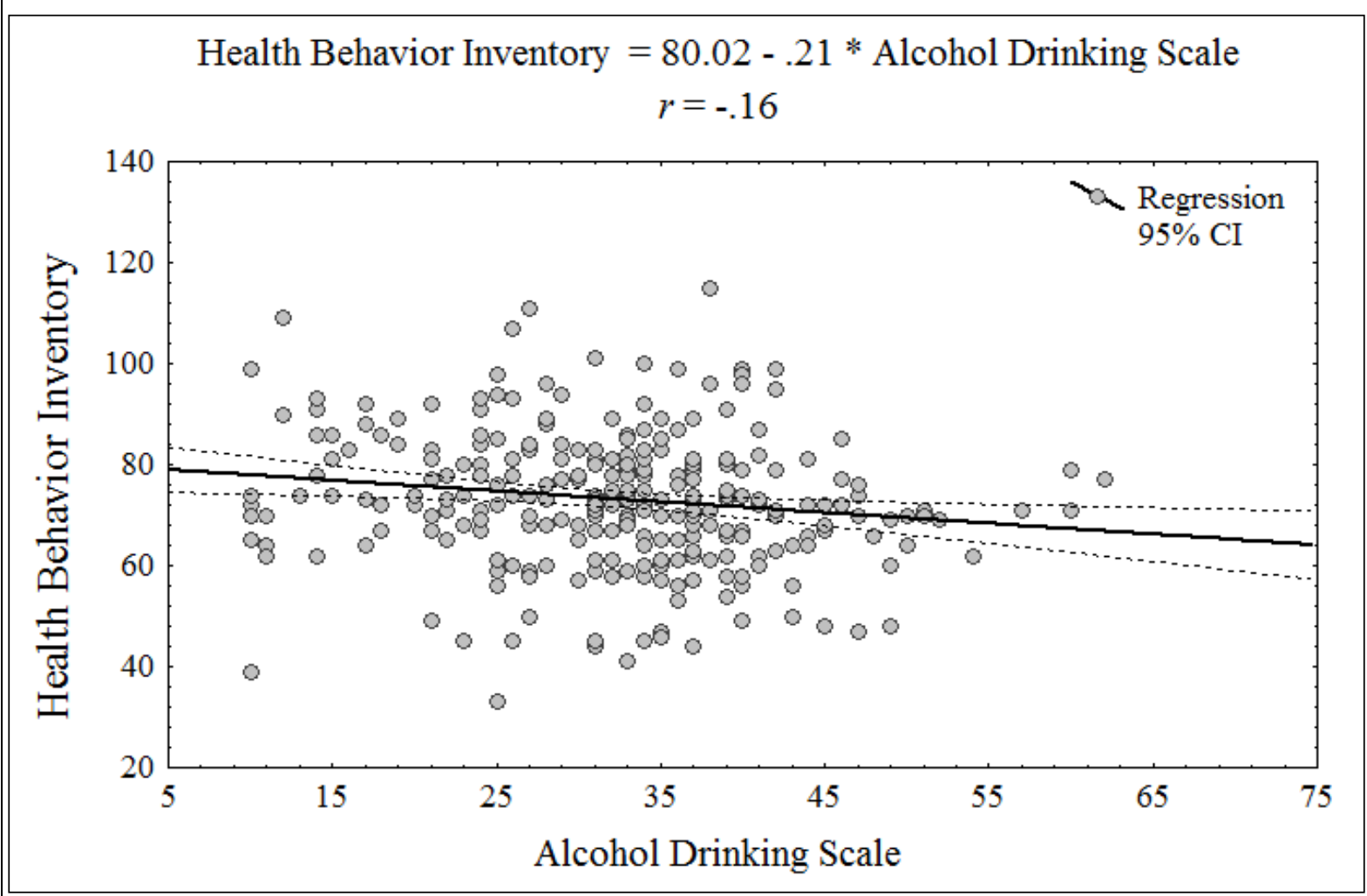

Source: Authors

Table 2: Differences between groups of students in Alcohol Drinking Scale and Health Behavior Inventory scales

\begin{tabular}{|c|c|c|c|c|c|c|c|c|c|c|}
\hline \multirow[b]{2}{*}{ Scales } & \multicolumn{2}{|c|}{ Female } & \multicolumn{2}{|c|}{ Male } & \multirow[b]{2}{*}{$\mathrm{t}(281)$} & \multicolumn{2}{|c|}{$\mathrm{PE}$} & \multicolumn{2}{|c|}{$\mathrm{TF}$} & \multirow[b]{2}{*}{$\mathrm{t}(281)$} \\
\hline & M & SD & M & SD & & M & SD & M & SD & \\
\hline Alcohol Drinking Scale & 27.56 & 9.16 & 33.96 & 9.75 & $-5.19 * * *$ & 33.74 & 9.89 & 31.21 & 9.98 & $1.98 *$ \\
\hline Health Behaviour Inventory & 77.64 & 13.42 & 71.22 & 12.89 & $3.82 * * *$ & 74.45 & 12.88 & 72.63 & 13.57 & 1.07 \\
\hline Healthy Habits Nutrition & 19.09 & 4.43 & 16.47 & 4.43 & $4.58 * * *$ & 17.44 & 4.46 & 17.21 & 4.65 & 0.40 \\
\hline Preventive Behaviour & 18.36 & 4.61 & 16.03 & 4.62 & $3.92 * * *$ & 17.27 & 5.04 & 16.50 & 4.58 & 1.27 \\
\hline Positive Adjustments & 20.45 & 3.80 & 20.04 & 3.88 & 0.82 & 20.80 & 3.56 & 19.88 & 3.95 & 1.85 \\
\hline Healthy Practices & 19.57 & 4.03 & 18.47 & 4.09 & $2.11 *$ & 18.81 & 3.67 & 18.81 & 4.28 & -.01 \\
\hline \multicolumn{11}{|c|}{ Note: $\mathrm{N}=283 ; * \mathrm{p}<0.05 ; * * * \mathrm{p}<0.001 ;$ PE: Physical Education; TF: Technical Faculty } \\
\hline
\end{tabular}


Figure 2: Mean results for female and male students in particular Health Behavior Inventory subscales

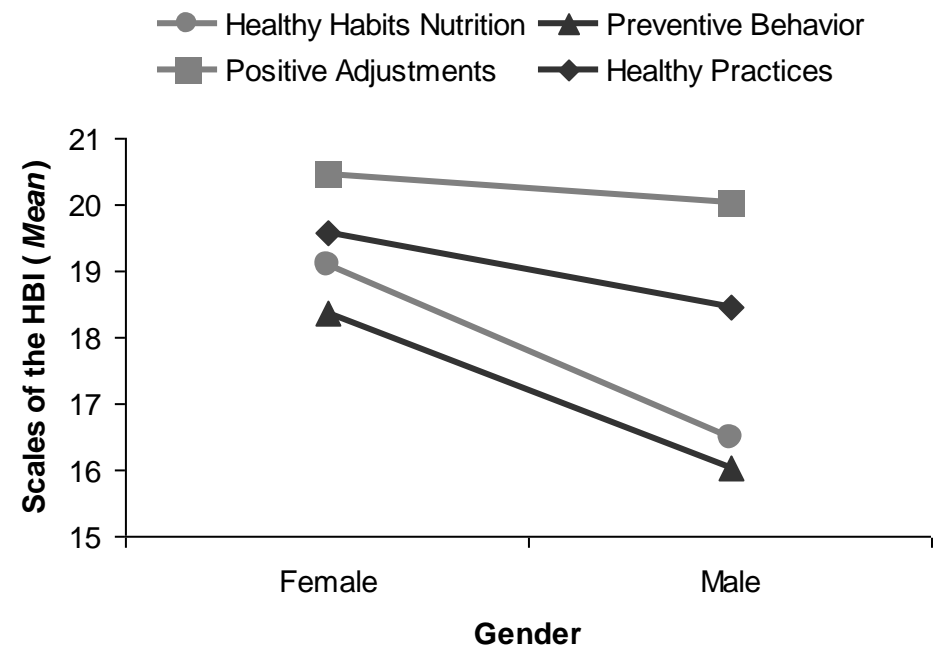

Source: Authors

Figure 3: Mean results for Physical Education and Technical Faculties students in particular Health Behavior Inventory HBI subscales
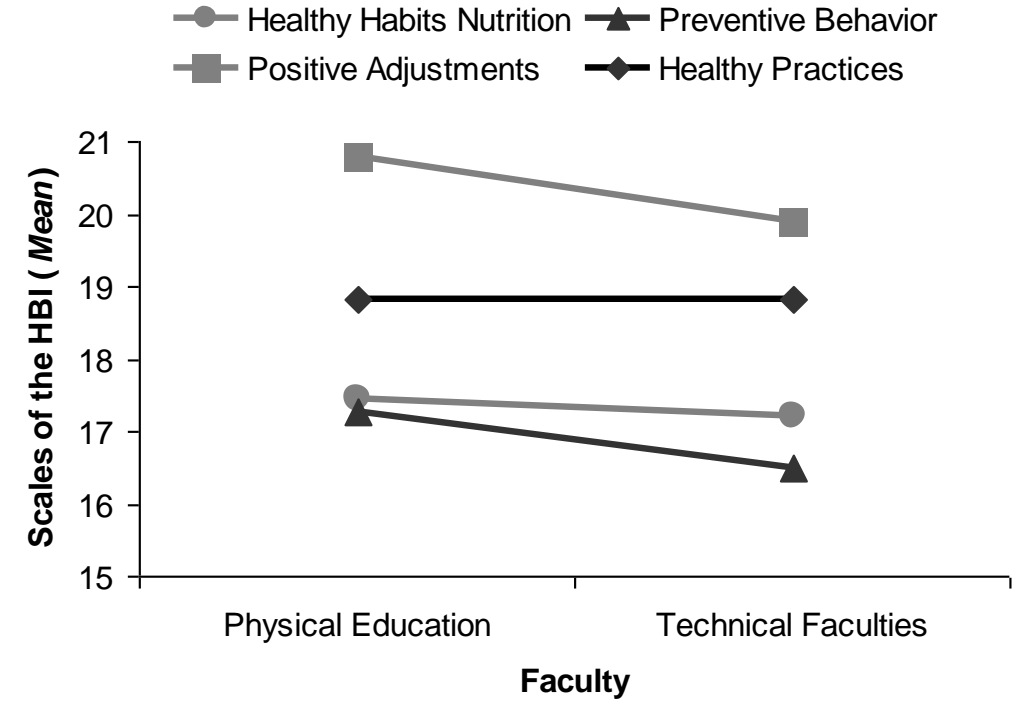

Source: Authors

In particular, physical activity showed a significant association with healthy eating patterns (Hendricks et al., 2004), which is not consistent with the present study. Here, we found that only alcohol drinking and preventive behavior differ physical education students from those who study technical faculties. De Vries et al. (2008) examined differences and similarities in five important preventive health behaviors: non-smoking, alcohol use, fruit consumption, vegetable consumption, and physical exercise, in a sample of 9,449 Dutch adults. Latent class analyses identified three clusters of people: a healthy, an unhealthy, and a poor nutrition cluster. However, it seems important to note that some studies have failed to show a relationship between health-related behaviors, whereas others have suggested associations between physical activity and healthy eating habits, or other multiple health behaviors (de Vries et al., 2008). 
In this study, male students drank significantly more alcohol than females, and were less likely to live healthily with regard to healthy diet, preventive behavior, and healthy practices. Positive adjustment, only, did not differ between gender samples, when differences were measured using the Student's t-test. However, the interaction effect in the present study suggested that gender could influence positive adjustment and healthy practices. Generally, females in this study demonstrated healthier lifestyles than the male students. This seems to be consistent with previous studies conducted in various countries (Binkowska-Bury et al., 2010; Harrell \& Karim, 2008; He et al., 2004, Kunttu \& Pesonen, 2013; Neumark-Sztainer, 1999; Pitel et al., 2010; Thom, 2003; Wicki et al., 2010).

The present results suggest that both gender scored rather poorly in total health-related behavior, since they assessed a mean $4^{\text {th }}$ standard ten (sten) score (Juczynski, 2009). Binkowska-Bury et al. (2010) used HBI (Juczynski, 2009) with a sample of 521 students from the south-eastern part of Poland and showed that $49 \%$ of respondents presented a low level of total health-related behavior. There is evidence that university students do not usually engage in a healthy lifestyle (Binkowska-Bury et al., 2010; He et al., 2004; Kunttu \& Pesonen, 2013; Neumark-Sztainer, 1999; Scott-Sheldon, Carey, \& Carey, 2008). The college years are associated with first experiences of adulthood, independence of parental control, and identity development. However, this period is also noted for the emergence of risky health behaviors, such as excessive alcohol drinking and drug use, risky sexual behavior, poor diet, and low level of physical activity, which place college students at risk for serious health problems (Scott-Sheldon et al., 2008; Wicki et al., 2010).

The university faculty can also have an impact on health behaviors of students, as suggested by the present findings. As expected, the PE students drank more alcohol than the TF students. This is consistent with numerous studies on the relationships between engagement in physical activity and alcohol drinking (e.g., Martens et al., 2006, 2008; Musselman \& Rutledge, 2010; Weaver et al., 2013; Yusko et al., 2008), and may be related to sensation-seeking, expectations about the effects of alcohol, perceived descriptive norms, athletic identity, sport-related achievement motivation (competitiveness, win and goal orientation), and specific drinking motives (e.g., social, conformity, coping, and mood enhancement). However, the PE students in this study showed a higher level of preventive behavior than their TF counterparts, as suggested by the multivariate analysis of variance in this study. Participation in physical activity is related to better self-image, self-esteem, coping skills, and positive mood (Cavill et al., 2006), which may be seen as a protective factor (Folke et al., 2002). It seems also likely, that the PE students demonstrated a higher level of consciousness of preventive practices, possibly because they learned information related to healthy lifestyle during classes at physical education faculty. Additional research is needed to fully explore the differences between PE students and those who study at other faculties.

The results of this study would be useful in developing targeted preventative programs (for male students and PE students in general) that could be implemented on college campuses. Although excessive alcohol drinking is truly a health problem at universities, it seems necessary to conduct general health education, health promotion, and health prevention together with alcohol prevention programs on college campuses (e.g., Diebold, Chappell, \& Robinson, 2000; Guillaumie, Godin, Manderscheid, Spitz, \& Muller, 2012; Larimer \& Cronce, 2007; Prince, Carey, \& Maisto, 2013).

The higher level of unhealthy behaviors, including higher rates of alcohol use, in PE students is cause for concern, with consequences not only for their individual health, but also for their professional effectiveness as future teachers of Health Education in schools. An adequate program preparing physical education teachers for health education should aim to practice various activities oriented towards a healthy lifestyle (Huk-Wieliczuk \& Marcinkowski, 2009). In particular, it seems necessary to improve the skills and professional knowledge of PE students in broad areas of alcohol-related topics and methods of prevention. According to the conception of Health Promoting Schools (Settertobulte, Bruun Jensen, \& Hurrelmann, 2001), current PE teachers must possess insights into such areas as the effects of alcohol, the root causes of various types of alcohol use and abuse, strategies promoting health, preventive measures, and solutions to alcohol-related problems. Perhaps most of all, PE teachers should be worthy role models for their pupils, following social learning theory (Bandura, 1977). In this perspective, it seems vital to seek new future directions for assisting PE students to achieve advanced levels of health education competencies (Riegelman \& Garr, 2011). 
There were certain limitations to this study. Firstly, the study relied on self-report measures. In addition, the study sample involved college students from the second year of a moderate sized university in Poland with limited ethnic diversity. Thus, the demographic and regional characteristics of this sample may not represent all other potential student populations. Additional research in a more random and more representative population of students (e.g., students from various universities and faculties, at various levels of education: undergraduate and graduate) is required to clarify these limitations.

\section{Conclusion}

The results of this study suggest that students lead a generally unhealthy lifestyle. Moreover, excessive drinking is related to low levels of both preventive behavior and healthy diets. Faculty and gender of students were related to differences in health-related behaviors. Physical Education students demonstrated a higher level of preventive behavior as well as higher alcohol use than their Technical Faculties counterparts. In addition, male students presented an unhealthier lifestyle than did their female counterparts. Thus, a special prevention program seems to be necessary at universities, especially among male PE students. The target of prevention could include excessive alcohol drinking, as well as a wide range of health-related behavior, such as healthy diet, preventive behavior, healthy practices, and positive adjustments.

\section{References}

Amir, D. (1987). Preventive behaviour and health status among the elderly. Psychology and Health, 1, 353-78. DOI: 10.1080/08870448708400337

Arria, A. M., Wilcox, H. C., Caldeira, K. M., Vincent, K. B., Garnier-Dykstra, L. M., \& O'Grady, K. E. (2013). Dispelling the myth of "smart drugs": Cannabis and alcohol use problems predict nonmedical use of prescription stimulants for studying. Addictive Behaviors, 38, 1643-1650. DOI: 10.1016/j.addbeh.2012.10.002

Bandura, A. (1977). Social learning theory. Englewood Cliffs, NJ: Prentice-Hall.

Binkowska-Bury, M., Kruk, W., Szymańska, J., Marć, M., Penar-Zadarko, B., \& Wdowiak, L. (2010). Psychosocial factors and health-related behavior among students from south-east Poland. Annals of Agricultural and Environmental Medicine, 17, 107-113.

Cavill, N., Kahlmeier, S., \& Racioppi, F. (2006). Physical activity and health in Europe: evidence for action. Copenhagen: WHO Regional Office for Europe.

Dams-O'Connor, K., Martens, M. P., \& Anderson, D. A. (2006). Alcohol-related consequences among women who want to lose weight. Eating Behaviors, 7, 188-195.

de Vries, H., van 't Riet, J., Spigt, M., Metsemakers, J., van den Akker, M., Vermunt, J. K., \& Kremers, S. (2008). Clusters of lifestyle behaviors: Results from the Dutch SMILE study. Preventive Medicine, 46, 203-208.

Diebold, C. M., Chappell, H. W., \& Robinson, M. K. L. (2000). A health promotion practicum targeting the college-age population. Nurse Educator, 25(1), 48-52.

Ezzati, M., Vander Hoorn, S., Rodgers, A., Lopez, A. D., Mathers, C. D., \& Murray, C. J. L. (2003). Estimates of global and regional potential health gains from reducing multiple major risk factors. The Lancet, 362(9380), 271-280.

Fabelo, J. R., Iglesias, S., Cabrera, R., \& Maldonado, M. T. (2013). Tobacco and alcohol consumption among Health Sciences students in Cuba and Mexico. MEDICC Review, 15(4), 18-23.

Folke, C., Carpenter, S., Elmqvist, T., Gunderson, L., Holling, C. S., \& Walker, B. (2002). Resilience and sustainable development: building adaptive capacity in a world of transformations. Ambio, 31(5), 437-40.

Gochman, D. S. (1988). Health behavior: Plural perspectives. In D. S. Gochman (Ed.), Health behavior: Emerging perspectives. (pp. 3 - 17). New York: Plenum Press.

Górska-Kłęk, L., Mełeszko, K., \& Berner, E. (2011). Pro-health behavior among students from the University School of Physical Education and the University of Economics, Acta Bio-Optica et Informatica Medica, 4(17), 268-74.

Guillaumie, L., Godin, G., Manderscheid, J.-C., Spitz, E., \& Muller, L. (2012) The impact of self-efficacy and implementation intentions-based interventions on fruit and vegetable intake among adults. Psychology \& Health, 27(1), 3050. DOI: $10.1080 / 08870446.2010 .541910$

Harrell, Z. A.T., \& Karim, N. M. (2008). Is gender relevant only for problem alcohol behaviors? An examination of correlates of alcohol use among college students. Addictive Behaviors, 33, 359-365.

He, K., Kramer, E., Houser, R. F., Chomitz, V. R., \& Hacker, K. A. (2004). Defining and understanding healthy lifestyles choices for adolescents. Journal of Adolescent Health, 35, 26-33.

Hendricks, K. M., Herbold, N., \& Fung, T. (2004). Diet and other lifestyle behaviors in young college women. Nutrition Research, 24, 981-991

Huk-Wieliczuk, E., \& Marcinkowski, J. T. (2009). Academies of Physical Education in Poland in view of current needs of health education. Problemy Higieny i Epidemiologii, 90(4), 470-76.

Juczyński, Z. (2009). Narzędzia pomiaru w promocji i psychologii zdrowia [Measurement tools in the health promotion and psychology]. Warszawa: Pracownia Testów Psychologicznych. 
Kozieł, D., Naszydłowska, E., Trawczyńska, M., \& Czerwiak, G. (2003). Youth`s healthy behavior as a direction for healthcare education, Polish Journal of Public Health, 113(3/4), 280-84.

Kunttu, K, \& Pesonen, T. (2013). Student Health Survey 2012: A national survey among Finnish university students. Helsinki: Finnish Student Health Service.

Larimer, M. E., \& Cronce, J. M. (2007). Identification, prevention, and treatment revisited: Individual-focused college drinking prevention strategies 1999-2006. Addictive Behaviors, 32, 2439-2468.

Lisha, N. E., \& Sussman, S. (2010). Relationship of high school and college sports participation with alcohol, tobacco, and illicit drug use: A review. Addictive Behaviors, 35, 399-407. DOI: 10.1016/j.addbeh.2009.12.032

Martens, M. P., Dams-O'Connor, K., \& Beck, N.C. (2006). A systematic review of college student-athlete drinking: Prevalence rates, sport-related factors, and interventions. Journal of Substance Abuse Treatment, 31, 305- 316. DOI: 10.1016/j.jsat.2006.05.004

Martens, M. P., Labrie, J. W., Hummer, J. F., \& Pedersen, E. R. (2008). Understanding sport-related drinking motives in college athletes: Psychometric analyses of the Athlete Drinking Scale. Addictive Behaviors, 33, 974-977. DOI: 10.1016/j.addbeh.2008.03.001

Michalik, M., \& Woitas-Ślubowska, D. (2012). Health-related behaviours among physical education students as an element of their preparation for health education in schools. Polish Journal of Public Health, 122(3), 246-50.

Musselman, J. R. B., \& Rutledge, P. C. (2010). The incongruous alcohol-activity association: Physical activity and alcohol consumption in college students. Psychology of Sport and Exercise, 11, 609-18. DOI: 10.1016/j.psychsport.2010.07.005

Neumark-Sztainer D. (1999). The social environments of adolescents: Associations between socioenvironmental factors and Health behaviors during adolescence. Adolescent Medicine, 10, 41-55.

Pitel, L., Madarasova Geckova, A., van Dijk, J. P., \& Reijneveld, S.A. (2010). Gender differences in adolescent healthrelated behaviour diminished between 1998 and 2006. Public Health, 12(4), 512-18. DOI: 10.1016/j.puhe.2010.05.005

Prince, M. A., Carey, K. B., \& Maisto, S. A. (2013). Protective behavioral strategies for reducing alcohol involvement: A review of the methodological issues. Addictive Behaviors 38, 2343-2351. DOI: 10.1016/j.addbeh.2013.03.010

Prohaska, T. R., Leventhal, E. A., Leventhal, H., \& Keller, M. L. (1985). Health practices and illness cognition in young, middle aged, and elderly adults. Journal of Gerontology, 40, 569-78.

Ray, A. E., Turrisi, R., Abar, B., \& Peters, K. E. (2009). Social-cognitive correlates of protective drinking behaviors and alcohol-related consequences in college students. Addictive Behaviors, 34, 911-917. DOI: 10.1016/j.addbeh.2009.05.016

Rehn, N., Room, R., \& Edwards, G. (2001). Alcohol in the European Region - consumption, harm and Policie. World Health Organization Regional Office for Europe.

Riegelman, R. K., \& Garr, D. R. (2011). Healthy people 2020 and education for health: What are the objectives? American Journal of Preventive Medicine, 40(2), 203-206. DOI: 10.1016/j.amepre.2010.10.017.

Romanowska-Tołłoczko, A. (2011), University students' lifestyles in the context of their health behaviors. Hygeia Public Health, 46(1), 89-93.

Scott-Sheldon, L. A. J., Carey, K. B., \& Carey, M. P. (2008). Health behavior and college students: Does Greek affiliation matter? Journal of Behavioral Medicine, 31, 61-70. DOI: 10.1007/s10865-007-9136-1

Settertobulte, W., Bruun Jensen, B., \& Hurrelmann, K. (2001). Drinking among young Europeans. Copenhagen: WHO Regional Office for Europe.

Sierosławski, J., (2004). Raport z badania ankietowego na temat używania substancji psychoaktywnych przez studentów: Studenci 2004 [The report of a survey study on psychoactive substances use among students: Students in 2004]. Warsaw: Krajowe Biuro ds. Przeciwdziałania Narkomanii.

Szczerbiński, R., Karczewski, J., \& Maksymowicz-Jaroszuk, J. (2011). Selection of health behaviors among students of college of physical education and tourism - dietary behaviors. Bromatologia i Chemia Toksykologiczna, 44(3), 409-414.

Thom, B. (2003). Risk-taking behaviour in men substance use and gender. London: Health Development Agency.

Weaver, C. C., Martens, M. P., Cadigan, J. M., Takamatsu, S. K., Treloar, H. R., \& Pedersen, E. R. (2013). Sport-related achievement motivation and alcohol outcomes: An athlete-specific risk factor among intercollegiate athletes. Addictive Behaviors, 38, 2930-36. DOI: 10.1016/j.addbeh.2013.08.021.

World Health Organization (2009). Global health risks global health risks WHO. Mortality and burden of disease attributable to selected major risks. Geneva: WHO. Retrieved from http://www.who.int/healthinfo/global_burden_disease/GlobalHealthRisks_report_full.pdf?ua=1

World Health Organization (2003). Diet, nutrition and the prevention of chronic diseases. WHO technical report series 916 Geneva: WHO. Retrieved from http://whqlibdoc.who.int/trs/WHO_TRS_916.pdf?ua=1

Wicki, M., Kuntsche, E, \& Gmel, G. (2010). Drinking at European universities? A review of students' alcohol use. Addictive Behaviors, 35, 913-924. DOI: 10.1016/j.addbeh.2010.06.015

Woynarowska, B., Mazur, J., Kołoło, H., \& Małkowska, A. (2005). Zdrowie zachowania zdrowotne i środowisko społeczne młodzieży w krajach Unii Europejskiej. Warszawa: Instytut Matki i Dziecka [Health behavior and the social environment of young people in the European Union . Warsaw: Mother and Child Institute].

Yusko, D. A., Buckman, J. F., White, H. R., \& Pandina, R. J. (2008). Risk for excessive alcohol use and drinking-related problems in college student athletes. Addictive Behaviors, 33, 1546-56. DOI: 10.1016/j.addbeh.2008.07.010 